\title{
Introduction: Negative Judgement: Ancient, Medieval, and Modern Perspectives
}

\author{
Sonja Schierbaum ${ }^{1} \cdot$ Mika Perälä $^{2}$
}

Published online: 27 January 2020

๑) Springer Nature B.V. 2020

We make judgements about various things. For instance, we may judge about factual, moral, or aesthetic matters, if we accept a statement as true, reject an action as blameworthy, or approve of a painting as beautiful. This special issue is dedicated to judgements of the first kind. In other words, we are interested in judgements that concern the truth and falsity of statements, or thoughts.

If one were to provide some key elements of a theory of judgement from the contemporary perspective of analytic philosophy, one could do so by pointing out some major assumptions of Gottlob Frege's philosophical logic, and the criticism that is levelled against them. In fact, we think that it is not possible for any scholar working on judgement in the analytic tradition to ignore Frege's position. ${ }^{1}$ His key claim is this: 'judging is the acceptance of the truth of a thought'. There are basically three issues about this definition, corresponding to the three notions used in the definition. The first touches upon the nature of thought as the primary bearer of truth, the second concerns the distinction between entertaining a thought and the act of judging (accepting), whereas the third bears on the nature of judging. In the following, we shall briefly comment upon the first two issues and their background so as to lay the necessary foundations for discussing the third in more detail, especially regarding negative judgement, which is the topic of this special issue.

Mika Perälä

mika.perala@helsinki.fi

Sonja Schierbaum

sonja.schierbaum@phil.uni-halle.de

1 Seminar für Philosophie, Martin-Luther-Universität HalleWittenberg, Emil-Abderhalden-Straße 26-27, 06108 Halle, Germany

2 Department of Philosophy, History and Art Studies, University of Helsinki, Unioninkatu 24 A, P.O. Box 24, 00014 Helsinki, Finland

\section{Truthbearers}

In Frege's view, the primary bearers of truth and falsity are thoughts (Gedanken). Since Frege takes thoughts, affirmative and negative ones alike, to be abstract, timeless entities, belonging to a sphere or realm of their own, he does not consider them to be mental acts. ${ }^{3}$ Many philosophers who follow Frege refer to these items as propositions. Although thoughts, so understood, cannot be perceived by the senses, they can nevertheless be grasped by more than one cognitive subject. For instance, if Anne thinks that snow is white and Ben thinks that snow is white, they have the very same thought. ${ }^{4}$ If thoughts were nothing but mental episodes belonging to the subject of these episodes, then according to Frege it could not be explained how there could ever be disputes among people about the truth of anything, since they would not even be talking about the same thing..$^{5}$

\section{Thought and Judging}

Frege distinguishes between entertaining a thought and judging its truth because he assumes that we can consider thoughts without taking them to be true or false. It follows that he posits

\footnotetext{
${ }^{1}$ Frege is often called the 'grandfather of analytic philosophy'. For an excellent commentary of Frege's philosophical logic, see Künne (2010).

2 Gottlob Frege, Der Gedanke (1918), in: Künne (2010, p. 92).

${ }^{3}$ Frege calls this sphere, a little unfortunately, the 'Third Realm' ('das Dritte Reich'). Künne (2010, pp. 502-507). It was, of course, not used by Frege in any political sense.

${ }^{4}$ For an interpretation of the major characteristics of Fregean 'thoughts' see Künne (2010, pp. 532-542).

${ }^{5}$ Frege, Der Gedanke (1918), in: Künne (2010, p. 101). It is quite another question whether the required independence of thoughts of a certain subject (Anna, Ben) also implies the independence of any cognitive subject: Could there be thoughts if there never was, is or will be any cognitive subject? Künne denies this. See Künne (2010, p. $514 \mathrm{ff})$.
} 
the two to be distinct kinds of mental acts. ${ }^{6}$ If Anne asks herself whether snow is white, then she is clearly entertaining the thought that snow is white without taking a stance on its truth value. If, by contrast, she asserts that snow is white, she not only entertains the thought that snow is white but also accepts and presents it as true. Frege emphasises that the 'force' of an assertion is to be distinguished from the propositional content of the sentence by means of which a thought is expressed.

Frege was not the first to introduce the foregoing approach to thoughts and judging. We can trace this approach back to the early Stoics who maintained that propositions (axiōmata), affirmative and negative alike, are mind-independent entities, and that they constitute contents for thought, or rational phantasia, as the Stoics have it. Furthermore, they held that when one makes a judgement, one gives an assent to a proposition. In contrast, if one withholds assent, one merely entertains a rational phantasia without committing oneself to the truth of the phantasia. ${ }^{7}$

What is the motivation for the Stoic-Fregean approach? The attraction of this approach lies chiefly in the objective understanding of propositions. First, a proposition, so understood, helps to explain how different subjects can share a thought, or disagree about it. Second, it helps to explain what different sentences, such as 'Is snow white?' and 'Snow is white,' have in common. Third, the proposition functions as the primary bearer of truth. Hence, one's mental act that snow is white is true because it expresses the true proposition 'Snow is white'.

\section{The Nature of the Act of Judging}

The Stoic-Fregean approach suggests that there are two kinds of propositions, affirmative and negative. Negative proposition, which says that it is not the case that $p$, is understood as the contradiction of affirmative proposition, and can be expressed formally as not- $p$. Negation, then, is taken to be a sentential function rather than a predicative function. The question that interests us for our present purposes is whether a corresponding distinction can be drawn between affirmative and negative acts of judging. In other words, we are considering the question of whether there are two different kinds of acts of judging, affirmative and negative, or merely one kind with two different kinds of content. In the following, we shall refer to the former alternative as the 'dualistic view', and to the latter as the 'monistic view'.

\footnotetext{
${ }^{6}$ Frege, Der Gedanke (1918), in: Künne (2010, p. 92).

7 There is one major difference between the Stoic and the Fregean views of proposition. While the Stoics suggest that a proposition may change its truth-value, Frege does not allow that. For a detailed study of Stoic propositions, see Frede (1974, pp. 32-44).
}

The Stoic-Fregean approach is monistic. There is only one kind of judging, but two different kinds of propositions: affirmative and negative. Understood in this way, affirmative judgement is a cognitive act whereby one gives assent to an affirmative proposition. By contrast, negative judgement is a cognitive act whereby one gives assent to a negative proposition. Hence, since the act of judging is the same in kind in the two cases, it is not necessary to introduce two different kinds of judging; there is only one kind which is affirmative by nature.

This view has fundamental implications for the conception of logic. One implication that recommends the monistic view is that it requires fewer rules of deduction than the dualistic view. According to monism, there is no need to stipulate a rule that allows one to pass from rejecting an affirmative proposition to accepting a negative proposition. ${ }^{8}$ By contrast, this rule is required if one takes the dualistic view. If the monistic view has advantages over the dualistic view in other respects, too, we have good reason to reject the dualist view, and give preference to the monistic view. ${ }^{9}$

In presenting this special issue, however, we suggest that monism does not seem to be preferable to dualism in every respect. One important, if somewhat trivial, point is that before Frege's influential anti-psychologist thrust, theories of judgement were not only concerned with logical, but with ontological, psychological, and epistemological issues as well. Take, for instance, the question of whether being is more fundamental than not-being, and the question of how the cognition of not-being is based on the cognition of being. Theories discussing these questions were typically, though not exclusively, dualist by nature, as the articles discussing Aristotle, Avicenna, Roger Kilwardby, William Ockham, Leibniz and Kant show. ${ }^{10}$ The same applies to those theories that propose to revise Frege's, such as Bertrand Russell's multiple relation theory and psychological theory, both of which are discussed in the final article of the present issue. Apart from the considerations given in those articles, we will adduce here two points that undermine Stoic-Fregean monism.

\footnotetext{
${ }^{8}$ Künne (2010, p. 576).

9 See Künne (2010, p. 578).

${ }^{10}$ Kant could perhaps be called a 'trialist' (with respect to both propositions and acts of judging) because in addition to affirmative and negative judgements, he pays special attention to a third qualitative category of judgements, namely infinite judgement, such as 'The soul is immortal'. In traditional, Aristotelian logic, infinite judgement is considered a special case of affirmative judgement because it is compounded by the affirmative copula 'is', and therefore presupposes the existence of its subject. For a discussion of infinite judgement in terms of 'metathetic judgement', see the article on Avicenna by Jari Kaukua. Kant argues that in transcendental logic, by contrast, infinite judgement must be separated from both affirmative and negative judgements. This shows that he goes beyond purely formal considerations in making distinctions between the different kinds of judgements. For references to Kant, see the articles by Mark Siebel and Hemmo Laiho in this special issue.
} 
First, consider the relations between affirmative and negative propositions. Why should one think that affirmative and negative propositions are on a par? Some ontological, linguistic and epistemic considerations suggest that affirmative propositions are more fundamental than negative propositions. For instance, Bradley argues that if affirmative propositions correspond to positive states of affairs, and negative propositions are on a par with affirmative propositions, there must be negative states of affairs in addition to positive ones. However, according Bradley, there are no good reasons to posit negative states of affairs. That is why he argues that we should not consider negative propositions as being on a par with positive ones. They are rather dependent upon the affirmative ones. His suggestion is that we understand a negative proposition as a denial of an affirmative proposition. ${ }^{11}$

Second, consider the relation between propositions and the act of thinking. Why should one assume that propositions do not depend on thinking for their capacity to be true or false? If propositions were independent from thinking, there should be some non-mental explanation for why a proposition can be true or false. However, it is difficult to see how such an explanation can be given. Since propositions, on the Stoic-Fregean conception, are absolute entities, unities of constituents rather than relations or sets, the explanation should be given by reference to features of the propositions themselves. However, it seems that neither the constituents of the propositions nor the relation in which they stand to each other provide the required explanation. Take for example the proposition 'Snow is white', which consists of the common noun 'snow' and the predicate 'being white'. It is evident that neither of the two constituents alone explains what makes the proposition true or false, and nor does the relation between the two if it is understood as a further constituent holding the two together. That is because according to the Stoic-Fregean understanding of propositions, being true or false is a property of the proposition itself rather than of some structural feature which is constitutive of that proposition. It remains unexplained, then, how a proposition can be true or false in the first place; after all, it seems to be a primitive feature of a proposition. ${ }^{12}$

The foregoing considerations suggest that there is good reason to consider an alternative to the Stoic-Fregean approach to propositions. In fact, most philosophers from Plato to Brentano apply an alternative approach, which does not posit propositions as mind-independent contents of thought. ${ }^{13}$ In their view, propositions are thoughts,

\footnotetext{
11 Bradley (1883, pp. 109-120).

12 In other words, the problem is how a proposition constitutes a unity that is truth-evaluable. This is called the "problem of the unity of the proposition'. For Frege's and Russell's failure to solve the problem, see Soames (2014a, pp. 26-32).
}

understood as mental acts. Thus, they take mental acts to be the primary bearers of truth.

Now, the question that the proponents of the alternative approach need to address is how thoughts and thereby locutions which are based on thoughts can be true or false. An answer is that a thought can be true or false because it is a mental act in which the cognitive subject predicates one thing of another, either affirmatively or negatively. This is the answer that can be found in Plato and Aristotle. ${ }^{14}$ This answer proved to be immensely influential. As the present special issue shows, it can be found in Avicenna, Roger Kilwardby, William Ockham, Leibniz, and Kant. Interestingly, the approach has also been adopted by some contemporary philosophers who explain the cognitive subject's capacity for representing things as being thus-and-so in terms of predicating something of something. ${ }^{15}$

Even if the foregoing alternative gives a reasonable answer to the question of what it is for a thought (or a representation in general) to be true or false, it seems to face difficulties when answering some other questions. For instance, it is not clear whether it can adequately explain thoughts and judgements which do not have a predicative structure, including compounds such as 'Snow is white and whiteness is a colour'; this question is briefly addressed in the articles on Aristotle and Avicenna. However, what is more fundamental for our present purposes is the question of whether that alternative can explain negative thoughts and negative judgements.

\section{Negative Propositions and Negative Judgements}

Basically, there are two alternative accounts. According to the first account, negative propositions consist in negative predication. Thus understood, negative propositions involve predicating not- $F$ of the subject term, for instance, not being white of snow. This account posits negative propositions on a par with affirmative propositions: affirmative predication and negative predication are two different kinds of predicating. This is the account that we find in most authors in the history of philosophy. Many authors follow Aristotle who accounts for affirmative predication in terms of combining the subject and the predicate terms, and negative predication in terms of separating the terms. This account as such does

\footnotetext{
13 Brentano goes further than any other theorist of judgement in that he does not posit propositions at all. In contrast, he argues that all judgements are objectual cognitive states. For this theory of judgement, see Brentano (1924 [1874], vol. II, pp. 38-82).

${ }^{14}$ For Plato, see e.g. Crivelli (2012, pp. 3-6); for Aristotle, see Crivelli (2004, pp. 6-12).

15 See e.g. Soames (2014b, pp. 95-96).
} 
not imply that negative predication constitutes a negative judgement, that is, a denial. Leibniz, for instance, is committed to this point in some of his texts, as is shown in the article in this issue. However, if one assumes that negative predication constitutes a negative judgement (as Aristotle assumes, according to some interpretations, though not the qualified one given in this issue), then it is consistent to suggest by analogy that affirmative predication constitutes an affirmative judgement.

According to the second account, by contrast, negative propositions consist in predicating not being true of an affirmative proposition $p$, which constitutes the denial of $p$. This account, then, suggests that negative propositions are based on affirmative propositions. As seen above, this is Bradley's view. A similar view can be found in more recent philosophy. ${ }^{16}$ The suggestion, then, is that affirmative and negative propositions involve two different kinds of predication that are of a different order. In either of the two accounts given above, however, negative judgement constitutes an act that is different in kind from affirmative judgement.

This is not the right place to go into the details of the foregoing alternative approach. However, it is important to see what motivates such an approach. It seems that a major reason why some logicians prefer this approach is that it appreciates the alleged psychological difference between affirmative and negative mental acts. In their view, then, a theory of logic should not be based purely on formal considerations, even if it chiefly concerns formal relations between predicates, and between propositions.

We hope that the foregoing overview helps to place the articles of this special issue in a general philosophical context. We wish to emphasise, however, that each philosopher ought to be studied in his or her own philosophical context. That is the approach applied in the articles that follow. To conclude this introduction, we will briefly introduce the key claims of each article. The articles are presented here and in this special issue according to the chronological order of their subject matter.

In his paper 'Affirmation and Denial in Aristotle's $D e$ interpretatione', Mika Perälä defends Aristotle's logic against the objection raised by modern logicians that it lacks a distinction between predication and assertion, and that predication implies assertion. Based on a study of the $D e$ interpretatione, Perälä argues that even if Aristotle defines what he calls simple assertion in terms of predication, he does not confound predication and assertion, at least not in the case of compound assertion.

In his paper 'Avicenna on Negative Judgement', Jari Kaukua provides an analysis of Avicenna's logical theory of negative judgement as a systematic development of the

$\overline{16}$ Soames (2014b, pp. 97-98). insights Aristotle laid out in the De interpretatione. Kaukua points out that in his logical treatises, Avicenna often admits that a full discussion of the subject matter would require psychological or metaphysical considerations, which he gives elsewhere, but does not refer the reader to the exact places. That is what Kaukua does in his article. By combining Avicenna's logical considerations with his psychological and metaphysical views, Kaukua offers a reconstruction of Avicenna's theory of negative judgement.

In his paper 'Roger Kilwardby on Negative Judgement', José Filipe Silva discusses Kilwardby's theory of judgement and considers its implications for Kilwardby's view on truth and falsity. Since Kilwardby develops his position by commenting on Aristotle's logical treatises, a central aim of Silva's paper is to show how Kilwardby addresses exegetical issues and offers solutions that go beyond Aristotle's alleged intentions. Silva argues that while Aristotle assumes that a true negative judgement does not presuppose the (real) existence of its subject, Kilwardby takes true negative judgements to have existential import, albeit one that is conceptual rather than real, as in the case of a true affirmative judgement.

In her paper 'Between the Supernatural and the Natural: Ockham on Evident Judgements' Sonja Schierbaum focuses on an aspect of Ockham's conception of intuition and evident judgement that has been neglected in the scholarly discussion. It is commonly assumed that by natural intuition, according to Ockham, we can make only affirmative judgements, whereas by supernatural intuition we can make both affirmative and negative judgements. However, Schierbaum shows that this way of contrasting the two is mistaken. She argues that, according to Ockham, natural intuition also enables us to make both affirmative and negative judgements.

In his paper 'Judgement in Leibniz's Conception of the Mind: Predication, Affirmation, Denial' Christian Barth argues for three claims. First, the act of judgement is at the centre of Leibniz's conception of the mind, because minds, according to Leibniz, strive to actualise innate knowledge concerning derivative truths, where actualising involves an act of judgement. Second, Leibniz distinguishes between predicative thoughts and judging their truth, and thereby holds a two-component account of judgement that involves both predication and alethic evaluation. Third, Leibniz understands the act of affirmative judgement in terms of establishing active dispositions, i.e. strivings, to make reasons available for future reasoning that aims at answering whether-questions. Barth concludes that the acts of affirmative as well as of negative judgement turn out to be acts of changing dispositions of memory.

In his paper 'Kant on Infinite and Negative Judgements: Three Interpretations, Six Texts, No Clear Result', Mark Siebel focuses on infinite judgement, which Kant proposes as a third quality of judgement, the first being affirmative and the 
second negative judgement. In Kant's view, an infinite judgement 'All S are non-P' differs from the affirmative 'All S are $\mathrm{P}$ ' because the former ascribes a negative predicate; and it differs from the negative 'No $\mathrm{S}$ is $\mathrm{P}$ ' because it has a richer content. Siebel puts three interpretations of this surplus content to six tests. Among other things, he examines whether these interpretations align with Kant's solution to the first antinomy, his conception of analyticity and the principle of complete determination. Siebel concludes that none of the interpretations succeed. It thus remains unclear what Kant, according to Siebel, had in mind when he introduced infinite judgements in addition to affirmative and negative ones.

In his paper 'Kant on Representing Negative States of Affairs', Hemmo Laiho investigates Kant's view of the cognitive role of perceptions, judgements and the three categories of Quality in representing negative states of affairs. Laiho addresses an apparent discrepancy in Kant's epistemological commitments: even if Kant, in his account of empirical cognition, seems to limit the legitimate application of the categories to things perceptually available to us, or, more generally, to positive cases, he also seems to hold that negative states of affairs, such as the absence of a thing, cannot be perceived. This discrepancy raises the question of how we can represent and make warranted empirical judgements about cases that lack positive instances in perception. In reply to the question, Laiho shows that the cognitive contribution of the categories, according to Kant, is most explicit in representing negative states of affairs, which requires overcoming the main limitation of sense perception, namely the incapacity of negative representation. Even so, Laiho concludes that positive representation is cognitively primary for Kant.

In his paper 'Russell on Negative Judgement', Anssi Korhonen discusses Bertrand Russell's changing views on negative judgement. Korhonen shows that Russell considers negative judgement in the context of three theories of judgement that he put forth at different times: a dual relation theory, a multiple relation theory, and a psychological theory of judgement. Korhonen singles out four issues for a more detailed discussion: the question of whether judgement comes in two kinds, acceptance and rejection, or whether there is only one judgement-quality; the question of the structure of negative judging; the problem of truth-making for negative facts; and the issue concerning the different roles of 'fact' in Russell's theories of truth. From his discussion there emerges a rough chronology of Russell's views on negative judgement during the period from 1903 to 1948.

Acknowledgements The guest editors Sonja Schierbaum (University of Hamburg and Martin Luther Universität Halle-Wittenberg) and Mika Perälä (University of Helsinki and University of Jyväskylä) are grateful to the Academy of Finland and the Deutscher Akademischer Austauschdienst for the Grants that they awarded, which made mutual visits abroad possible and thereby enabled the collaborative editorial work necessary to complete this special issue. The guest editors are also grateful to Michael Walschots for revising the English language of this introduction.

\section{References}

Bradley FH (1883) Principles of logic. Oxford University Press, Oxford Brentano F (1924 [1874]) Psychologie vom empirischen Standpunkt. Zweite Auflage, 2 Bände. Felix Meiner Verlag, Leipzig

Crivelli P (2004) Aristotle on truth. Cambridge University Press, Cambridge

Crivelli P (2012) Plato's account of falsehood: a study of the Sophist. Cambridge University Press, Cambridge

Frede M (1974) Die stoische logic. Vandenhoeck \& Ruprecht, Göttingen

Künne W (2010) Die Philosophische Logik Gottlob Freges-Ein Kommentar. Klostermann, Frankfurt/M

Soames S (2014a) Why the traditional conception of propositions can't be correct. In: King JC, Soames S, Speaks J (eds) New thinking about propositions. Oxford University Press, Oxford, pp 25-44

Soames S (2014b) Cognitive propositions. In: King JC, Soames S, Speaks J (eds) New thinking about propositions. Oxford University Press, Oxford, pp 91-124

Publisher's Note Springer Nature remains neutral with regard to jurisdictional claims in published maps and institutional affiliations. 